\title{
Review
}

\section{Management of Pain in Parkinson's Disease}

\author{
Carsten Buhmann ${ }^{\mathrm{a}, *}$, Jan Kassubek ${ }^{\mathrm{b}}$ and Wolfgang H. Jost ${ }^{\mathrm{c}}$ \\ ${ }^{a}$ Department of Neurology, University Medical Center Hamburg-Eppendorf, Hamburg, Germany \\ ${ }^{\mathrm{b}}$ Department of Neurology, University of Ulm, Ulm, Germany \\ ${ }^{\mathrm{c}}$ Parkinson-Klinik Ortenau, Wolfach, Germany
}

Accepted 18 May 2020

\begin{abstract}
Pain is a very frequent symptom with influence on the quality of life in Parkinson's disease (PD), but is still underdiagnosed and commonly treated only unsystematically. Pain etiology and pain character are often complex and multicausal, and data regarding treatment recommendations are limited. Pain can be primarily related to PD but frequently it is associated with secondary diseases, such as arthrosis of the spine or joints. However, even basically PD-unrelated pain often is amplified by motor- or non-motor PD symptoms, such as akinesia or depression. Beyond an optimization of anti-parkinsonian treatment, additional pain treatment strategies are usually needed to properly address pain in PD. A careful pain history and diagnostic work-up is essential to rate the underlying pain pathophysiology and to develop a targeted therapeutic concept. This review gives an overview on how pain is treated in PD patients and how patients assess the effectiveness of these therapies; here, the manuscript focuses on pathophysiology-driven suggestions for a multimodal pain management in clinical practice.
\end{abstract}

Keywords: Parkinson's disease, pain, therapy, analgetics, pathophysiology, non-motor symptoms

\section{INTRODUCTION}

In Parkinson's disease (PD), impairment of quality of life $(\mathrm{QoL})$ is frequently related to a variety of nonmotor symptoms even more than to motor-symptoms [1-4]. Pain was realized to be among the most frequent non-motor complaints, affecting $68-95 \%$ of PD patients (depending on the design, questionnaires or types of pain assessed) across all clinical stages [4-7].

The etiology and phenotype of pain in PD patients is complex, often multi-factorial, and-even in cases with apparently PD-unrelated pain, e.g., due to arthrosis of spine or joints-amplified by motor- or

\footnotetext{
*Correspondence to: Prof. Dr. Carsten Buhmann, Department of Neurology, University Medical Center Hamburg-Eppendorf, Martinistrasse 52, 20246 Hamburg, Germany. Tel.: +49 407410 52771; Fax: +49 407410 45780; E-mail: buhmann@uke.de.
}

non-motor PD symptoms such as akinesia, rigidity, or depression. There are different classifications of pain subtypes in PD $[8,9]$ which share some aspects but differ in others, indicating that a universal categorization is not available yet.

Data regarding the real-life therapy of pain in PD are limited. One reason might be related to the observation that many patients do not ascribe their pain to PD and therefore prefer to consult specialists other than neurologists, e.g., orthopedists or general practitioners [4]. Accordingly, treatment is frequently more dependent on the specialty of the medical professional consulted than based on the underlying pathophysiology.

This review intends to give an overview on pain classification, pain assessment, pain presentation, and the existing therapy landscape and focusses on pathophysiology-driven recommendations of pain treatment in PD. 


\section{PAIN PATHOPHYSIOLOGY AND CLASSIFICATION IN PD}

Pain can be related to PD itself and occurs as 'central' pain as a result of an objective painprocessing and pain-perception disturbance within ascending and descending pathways [10]. Pain experience results from a complex integration of sensory-discriminative, affective-motivational, cognitive-evaluative, and autonomic-neuroendocrine processes [11]. As such, many of the pain processing structures are directly involved in the spread of the PD pathoanatomy in the nervous system at various neuropathological stages [12], given that every localization of pain has been described in PD [11]. The basal ganglia are substantially involved in ascending and descending central pain processing, and dopamine decrease induces a lowering in the threshold for multimodal pain [13]. In addition, local neurodegenerative changes in spinal excitability with painful hyperactivity in primary afferent nociceptors or a diminished dopaminergic descending inhibition seem to be pathophysiologically relevant in PD [14-17]. However, results of studies investigating the influence of dopaminergic replacement therapy on objective pain thresholds yield controversial findings for levodopa [18-21]. Furthermore, other areas neurodegeneratively affected in PD [12] (such as certain cortical regions including limbic structures, thalamus, brainstem nuclei, the periaqueductal grey matter, and the spinal cord) contribute to abnormal central nociceptive pain processing [13]. Additionally, molecular changes of the cytoskeleton and mitochondria in PD might lead to hyperactivity of the nociceptor resulting in neuropathic pain [14] and increased pain sensitivity as the result of a reduced nociception threshold [22, 23].

However, pain far more frequently presents not as 'central' but as musculoskeletal/nociceptive pain in PD patients, and in about half of the (in average elderly) PD population, it is related to secondary diseases such as spine or joint arthrosis $[4,5]$. Pain related to arthrosis of the spine or joints likely is amplified by akinesia and rigidity, but there is no clear relationship of severity of motor symptoms and pain reported [4, 5, 7, 24]. Accordingly, pain and motor impairment do not correlate well [25], suggesting that both symptoms do not necessarily share the identical pathogenetic mechanisms [14]. Nevertheless, it has to be kept in mind that musculoskeletal pain preferentially of one side of the body, e.g., as 'shoulder-arm-syndrome', is a very typical early presentation of akinesia and rigor in PD [26] and frequently might be missed.

Female gender, dyskinesia, postural abnormalities, motor complications, and depression have been found as predictors for pain in PD (review in [27]). Reports on gender differences regarding pain perception [28] support the hypothesis that genetic variants might contribute to pain susceptibility [29] or other pain aspects such as time of onset [30]. Common comorbidities in PD patients known to trigger pain include diabetes mellitus, osteoporosis, rheumatic diseases and arthritis [31-33].

Today, the classification of pain in PD by Ford [8, 34] is still the most commonly used: it differentiates pain into musculoskeletal, radicular/neuropathic, dystonia-related, akathic discomfort/pain, and central pain.

\section{PAIN PRESENTATION AND ASSESSMENT IN PD}

Most epidemiological data are based on questionnaires which were not specifically validated for PD patients so that results have to be interpreted with caution. The King's Parkinson's disease pain scale (KPPS) is to date the only questionnaire that is specifically calibrated and validated for PD and is highly recommended to qualitatively and quantitatively assess pain and to ascribe the pain pathophysiologically. The scale contains seven different pain domains comprising musculoskeletal pain, chronic pain (central and visceral), fluctuation-related pain, nocturnal pain, oro-facial pain, discolouration or oedema/swelling and radicular pain as well as 14 subcategories [35]. This assessment tool is based on the pain classification according to Ford [8] but also considers pain types of other classifications such as motor fluctuations or visceral pain [9].

A large population-based cohort study with 33.388 participants revealed that subjects developing PD within a mean-follow-up of three years more frequently had pain before PD diagnosis, suggesting pain might be a very early non-motor-sign in some PD patients [36]. Accordingly, 5.5\% of PD patients reported pain as their first symptom [4]. In a recent large questionnaire-based study with $2.814 \mathrm{PD}$ patients in Germany, spinal-paravertebral pain was reported to be the most frequent form of pain, followed by joint and musculoskeletal pain and for every localization, pain occurrence was higher in females compared to males [28]. These observations are in 
line with earlier findings in smaller cohorts of 96, 176 , and 181 patients, respectively, describing musculoskeletal pain as the most frequent pain subtype in PD $[4,5,37]$ that is mainly localized in the back or joints and often occurs as pain attacks [4]. While nociceptive pain was considered to be common, neuropathic pain character has only been reported by a minority of PD patients with pain [4] but still occurs more frequently than in the general population [9]. PD-associated pain has been found to be chronic in at least two thirds of the affected patients [4, 31]. Poorer balance performance, a shorter disease duration, and poorer health-related QoL were found to be independently associated with pain severity in PD [38].

In addition, there are some specific pain syndromes in PD which have to be kept in mind, including the so-called coat-hanger pain that occurs in cases of pronounced orthostatic dysregulation and although it is more frequent in multisystem atrophy (MSA) it can occur also in PD and is often associated with strong headache and neck pain [39]. Furthermore, pain due to constipation which is frequent in PD can cause abdominal pain.

Noteworthy, the patients often will not report on pain by themselves because they do not refer the pain to their PD symptoms complex [40] so that taking a careful pain history should be an essential part of a consultation with a given PD patient. To explore non-motor symptoms might be a particular challenge in very advanced disease, i.e., finally in the palliative stage of PD treatment. Here, a portfolio for pain management is an important element of the disease-specific, multidisciplinary conceptualization of palliative care for which specific tools may be needed such as the application of pain observation tools in PD with dementia (often adapted from generic tools) that could identify specific palliative care needs in PD [41]. Such awareness for pain (which might not be communicated verbally) needs guidelines for the complete team of health care professionals involved $[42,43]$.

\section{GENERAL ASPECTS OF PAIN TREATMENT IN PD}

Despite the high prevalence of pain in PD, literature data suggest that only up to a maximum of $50 \%$ of PD patients receive at least some type of pain therapy [4-6, 31, 44].
Still, the fundament of pain therapy should be an optimized dopaminergic treatment which can improve pain related to insufficient dopaminergic supply such as akinesia and/or rigidity [45, 46], pain due to dopaminergic over-supply such as dyskinesia and/or dystonia [22], or central pain that is dopamine-sensitive [9]. This concept was reported to be effective in about $30 \%$ of PD patients [4]. A standardized levodopa test can be helpful to decide whether the pain is dopaminergic responsive or not, but any result of this short-term effect must always be interpreted with caution so that the long-term assessment of pain under dopaminergic therapy over several weeks remains essential [27].

A systematic review and meta-analysis including databases from January 2014 until February 2018 investigated the efficacy of a variety of novel, complimentary, and conventional treatments for pain in PD and found the greatest reduction in pain for safinamide, followed by cannabinoids and opioids, multidisciplinary team care, COMT-inhibitors, and electrical and Chinese therapies, while the weakest effects were obtained for dopaminergic agonists and miscellaneous therapies [47]. Table 1 gives an overview of larger randomized controlled trials (RCT) of antiparkinsonian drugs and opioids assessing the effect on pain in PD patients.

However, it was not antiparkinsonian medication but rather pain killers such as nonsteroidal antiinflammatory drugs (NSAID) that have been reported by PD patients to be mostly used to treat their pain $[4,28]$ with frequencies of $70 \%$ for ibuprofen and $36 \%$ for diclofenac [4], without gender difference [28]. They were self-rated as most effective analgetic drugs by the majority of patients $(77.9 \%)$ with pain relief exceeding $50 \%$ in two-third of the patients [4]. Other drugs widely used by PD patients are the pyrazolone derivate metamizol [4, 28, 48], with reported application in $16 \%$ of PD patients [4] and cyclooxygenase-2 (COX-2) inhibitors [28]. Furthermore, other pain killers such as paracetamol, opioid-derivates, and drugs for neuropathic pain such as pregabaline and amitriptyline are frequently applied [4]. Opiods seem to be applied more often to males than to females [28] and pregabaline is reported to be given preferentially in PD patients with neuropathic pain $[4,48]$. According to another study, pregabaline and metamizole rank among the top ten of drugs prescribed for PD patients in Germany [48]. Furthermore, antidepressants [49] and cannabinoids $[50,51]$ have shown analgetic effects in $\mathrm{PD}$ patients. 
Table 1

Shows larger randomized controlled trials (RCT) of antiparkinsonian drugs and opioids assessing the effect on pain in PD patients

\begin{tabular}{|c|c|c|c|c|}
\hline Treatment & $\begin{array}{l}\text { Study design and applied } \\
\text { scales for pain }\end{array}$ & Patients \& Methods & $\begin{array}{l}\text { Results Means with (SD), (range) or } \\
\text { (CI) }\end{array}$ & References \\
\hline Pramipexole & RCT, VAS-P & 138 vs. 148 controls & $\begin{array}{l}-3,3(-8.9 \text { to } 0.3) \text { vs. }-2.4(-8.9 \text { to } \\
\text { 2.6) Group comparison }-1.3(-3.3 \\
\text { to } 0.8) p=0.19\end{array}$ & $\begin{array}{l}\text { Barone et al. } 2010 \\
\text { [96] }\end{array}$ \\
\hline Safinamide & RCT (post hoc), PDQ-39 & 440 vs. 438 controls & $\begin{array}{l}\text { reduction of the number of } \\
\text { concomitant pain treatments of } \\
23.6 \% \text { [5\% confidence interval } \\
\quad(\mathrm{CI}): 41.1 \%, 1.0 \% ; p=0.0421] \\
\text { PDQ-39: item } 37(-0.26 \text { vs. }-0.07 ; \\
\quad p=0.0009) \text {, item } 38(0,19 \text { vs. } 0.1 ; \\
p=0.1585), \text { item } 39(-0.18 \text { vs. }- \\
0.03 ; p=0.0060)\end{array}$ & $\begin{array}{l}\text { Cattaneo et. al. } 2017 \\
\text { [63] }\end{array}$ \\
\hline Entacapone & RCT, PDQ-39 & 281 vs. 274 controls & $\begin{array}{l}(0.04) \text { vs. } 0.1(0.04) ; p=0.9 \\
\quad \mathrm{SMD}=1.81, p<0.0001\end{array}$ & Olanow et al. [64] \\
\hline Oxycodone & RCT, KPPS & 88 vs. 106 controls & $\begin{array}{l}5.0(95 \% \text { CI } 4.5 \text { to } 5.5) \text { versus } 5.6 \\
\text { (5.1 to } 6.0) \text {. Difference }-0.6,95 \% \\
\text { CI }-1.3 \text { to } 0.0 ; p=0.058)\end{array}$ & $\begin{array}{l}\text { Trenkwalder et al. } \\
\text { [78] }\end{array}$ \\
\hline Pardoprunox & RCT (post-hoc), VAS-P & 140 vs. 133 controls & $\begin{array}{l}\text { During OFF time }-2.2(2.7) \text { vs. }-1.0 \\
\quad(2.7), \text { no p-values given } \\
\text { During ON time }-2.3(2.8) \text { vs. }-0.5 \\
\quad(3.0), \text { no } p \text {-values given }\end{array}$ & Rascol et al. [65] \\
\hline \multirow[t]{2}{*}{ Rotigotine } & RCT, Likert pain scale & 178 vs. 88 controls & $\begin{array}{l}-0.9(\mathrm{SD} 2.2) \text { vs. }-0.1 \text { (SD 2.3), } \\
p=0.004 \\
\text { Difference }-0.77[-1.28 \text { to }-0.25]\end{array}$ & $\begin{array}{l}\text { Trenkwalder et al. } \\
\text { [72] }\end{array}$ \\
\hline & $\begin{array}{l}\text { RCT ( post-hoc), Likert } \\
\text { pain scale }\end{array}$ & 178 vs. 88 controls & $\begin{array}{l}\text { 'any pain': }-0.88 \text { [95\% CI: }-1.56 \text {, } \\
-0.19], p=0.013) \\
\text { 'moderate-to-severe' pain: }(-1.38 \\
\text { [-2.44, }-0.31], p=0.012 \\
\text { UPDRS III or PDSS-2 responders } \\
\text { showed greater improvement in } \\
\text { pain than non-responders }\end{array}$ & Kassubek et al. [73] \\
\hline
\end{tabular}

Amongst non-pharmacological treatments for pain, positive effects have been reported for deep brain stimulation (DBS) [52-56], yoga [57], or acupuncture $[4,58]$. Physiotherapy and rehabilitation were mentioned by the patients as particularly effective [4], in agreement with the high prevalence of musculoskeletal pain. If necessary, additional behavioral or pain management therapy or other complementary methods such as chiropractic or osteopathy can be considered to accompany and individually adapt treatment to the patient's symptoms [27]. Less invasive procedures, such as periradicular therapy (PRT), can be used for therapy-resistant radicular pain symptoms [27], whereas surgical procedures can be considered in individual cases, in particular joint surgery for accompanying rheumatic diseases [59], spinal surgery therapies for highgrade spinal canal stenoses or root compression syndromes that cannot be managed otherwise, as well as osteosynthesis for higher-grade spondylolisthesis or vertebral body injuries [27]. Because surgery in PD is often not more effective compared to less invasive procedures $[4,47]$ but is associated with higher risks, frequently resulting in long-term hospitalization and increased postoperative mortality and morbidity [59, $60]$, application should be restricted to individual cases.

Multimodal pain therapy is usually recommended [61]. Orthopedists and general practitioners were reported to be the most frequent specialties consulted for pain therapy in $\mathrm{PD}$, whereas neurologists do not seem to be regarded as the primary consultant. Best therapeutic efficacy was self-reported in conjunction with medical rehabilitation, physiotherapy, and the use of analgesics, mainly NSAIDs [4, 54], but data are unfortunately still limited so that no clear-cut recommendation regarding type of supportive therapy can be given yet [4, 27, 40, 47]. Because for both, pharmacological and supportive pain therapies, only short-lasting effect have been reported [4], a continuous or repetitive treatment seems to be mandatory for ongoing efficiency.

In the following, we suggest treatment options for specific PD-associated pain types based on the given or assumed pathophysiology and the available data regarding the efficiency of pharmacological and non- 


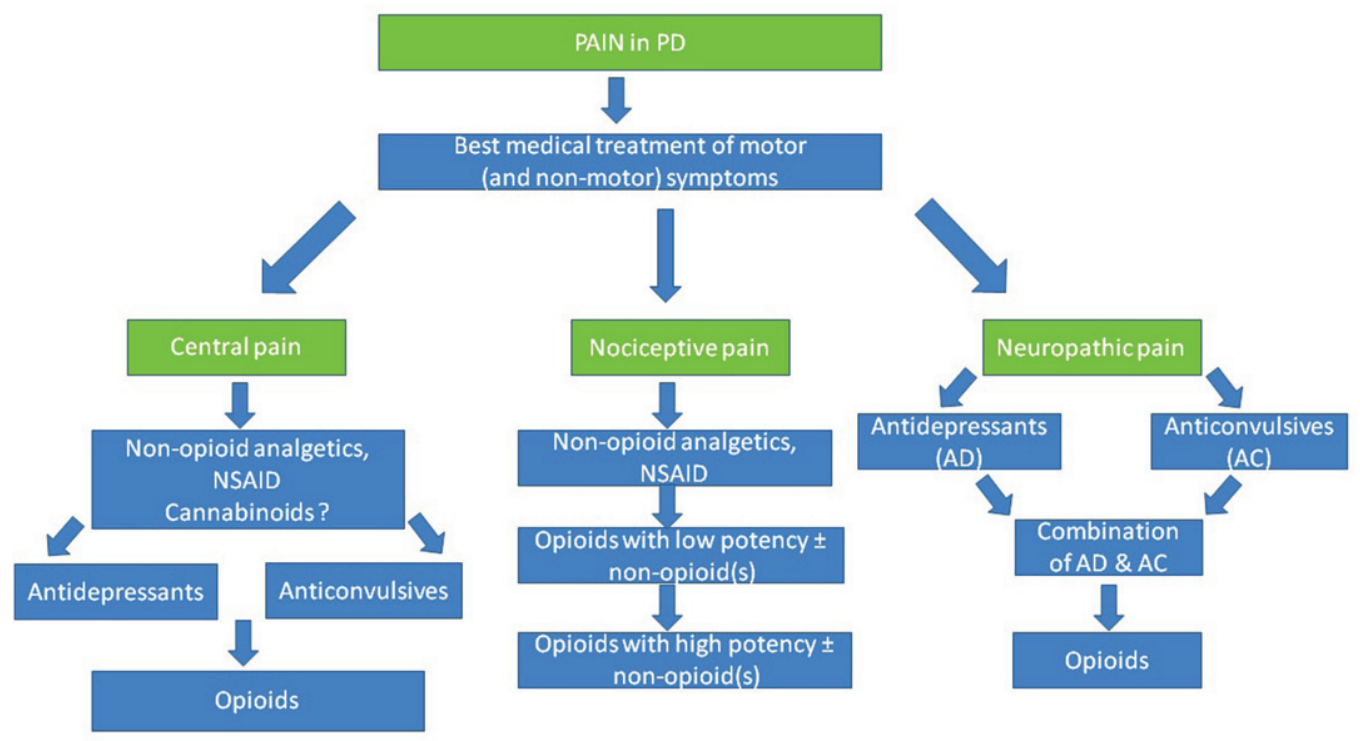

Modified according to WHO three-steps pain treatment scheme

Fig. 1. Algorithm suggested for pain therapy in PD.

pharmacological treatment options. Figure 1 shows an algorithm suggested for pain therapy in PD.

\section{PAIN DUE TO FLUCTUATIONS, DYSKINESIA OR DYSTONIA}

To reduce potentially pain provoking motor fluctuations and dyskinesias, the optimization of therapy aiming to smoothen dopaminergic plasma level is recommended. The use of prolonged acting dopamine agonists [62] or substances reducing the dopamine degradation such as MAO-B [63] or COMT [64] inhibitors are thought to reduce painful motor fluctuations during day- and night-time as well as early-morning akinesia. PD patients with motor fluctuations, who received the finally not approved partial dopamine D2 agonist Pardoprunox as adjunct therapy to levodopa, showed in a post-hoc analysis of a RCT a greater decrease in VAS pain scores compared to placebo [65]. Amantadine might be helpful for painful dyskinesia, but data is missing.

As escalation therapies, continuous administration of apomorphine or levodopa/carbidopa-intestinal-gel (LCIG) via a pump may be considered. In the GLORIA registry study, LCIG therapy over six months, "painful muscle cramps or spasms" improved, and LCIG over 12 months was associated with fewer painful dyskinesias [66]. Furthermore, prospective seven-year data of 59 patients with LCIG therapy have shown a decrease of $78 \%$ in dyskinesia related pain [67]. Apomorphine is suggested in painful akinetic phases $[62,68]$, botulinum toxin in painful on- and off dystonia [68-70]. Therapy-resistant dystonia can also respond to DBS of the subthalamic nucleus (STN) [56]. STN-DBS has been reported to improve pain in up to $80 \%$ of patients compared to the condition prior to surgery $[52,54]$, related to improvement of dystonic and musculoskeletal $[53,55]$ pain but not related to central or neuropathic pain [53]. However, new and especially musculoskeletal pain developed in most patients at new locations under DBS, becoming a long-term strain [55, 71]. Noteworthy, pain reduction was found to be independent of improvement of motor symptoms [55], suggesting an additional specific stimulation-related pain modulating central effect.

Besides their effects on motor function, some antiparkinsonian drugs might have an additive or substance-specific effect on pain. One substance is rotigotine. In a placebo-controlled study in PD patients with insufficient control of early morning motor disturbances, treatment with rotigotine led to slight but significantly lesser pain. It is unclear whether this is due to the additional positive effect on motor function and sleep or an independent substance-specific analgetic effect [72]. A post-hoc analysis demonstrated that patients with moderate to severe pain and with a motor response of at least $30 \%$ in the UPDRS III scale especially 
showed greater improvement in pain [73]. Another placebo-controlled study revealed that treatment with rotigotine in patients with advanced disease stage led to improvement of pain intensity and fluctuationrelated pain after 12 weeks [74].

A second substance with a potential specific effect on pain might be safinamide. In a post-hoc analysis based on pooled data of two large RCTs, safinamide applied as add-on therapy to levodopa treatment was associated with less consumption of pain medication compared to placebo (about 24\%) and a significant reduction of pain in two of three sub-items of the PDQ-39 scale reflecting musculoskeletal and neuropathic pain $[63,75]$. Noteworthy, in the safinamide group a slightly higher percentage of patients had additional pain medication at study baseline. In summary, this limited benefit needs to be confirmed by dedicated future studies.

In conclusion, amongst dopaminergic drugs, rotigotine and safinamide might be of particular benefit for PD patients with pain, although it has to be kept in mind that the data were derived from post-hoc analyses from studies with different read-outs.

\section{CENTRAL PAIN}

Recommendations regarding treatment of central pain in PD are difficult due to the unsharp definition of this type of pain, the unclear underlying pathophysiology and lack of clinical data.

In future, cannabinoids might play an increasing role in treatment of central pain, because the endocannabinoid system and the distribution of cannabinoid receptors in basal ganglia structures involved in pain processing suggest a potential analgetic benefit [76]. However, to date clinical data on the use of cannabinoids to treat pain of different etiology in PD patients are weak and do not yet allow sufficient conclusions to be drawn. In two open, uncontrolled observational studies a reduction in pain intensity, assessed with different short pain scales not yet PD-validated, was reported after smoking of 0.5 and 1 gram of cannabis [50,51] and after long-term cannabis [51].

In chronic and severe pain prolonged-released oxycodone in combination with naloxone is an option that has been proven to be efficient to reduce different types of pain in PD patients, including central pain $[77,78]$. A lower dose of oxycodone/naloxone $(10 / 5 \mathrm{mg})$ [78] did not induce constipation or sedation while a higher dose (18/8 $\mathrm{mg}$ ) [79] caused nausea and constipation. As both doses were efficient and motor function did not deteriorate, lower doses of oxycodone should be preferred. Naloxone has a local competitive antagonism in the GI and helps to reduce the constipating effect of the opiate without impairing the central analgesic effect [77].

Glutamate is believed to play a crucial role in central pain modulation in PD [80] with an increase in glutamate release leading to cortical hyperactivity and consecutively hyperalgesia and allodynia. Therefore, amantadine as glutamate-antagonist might reduce central pain in $\mathrm{PD}$, but data are missing.

Noteworthy, it has been proven in animal studies that the ion channel-active anticonvulsants gabapentine and pregabaline reduce a potassium-induced release of the excitatory neurotransmitter glutamate [81]. Because gabapentine is tolerated well in PD and might even have a positive influence on motor symptoms [82, 83], gabapentine and also pregabaline might be recommended as treatment option for central pain in $\mathrm{PD}$, although clinical data are lacking.

Furthermore, the antidepressant duloxetine has been described to be effective on central pain in PD in an open, uncontrolled study [49].

A non-interventional multicenter observational study described a positive effect of rotigotine on the subjective affective (central) pain perception of PDassociated pain [84].

Some studies have found STN-DBS to modulate thresholds for detecting thermic [85] or mechanic stimuli $[52,71]$ but the majority did not $[52,84]$, so that modulation of central pain by STN-DBS is not proven. However, the new technique of lowfrequency DBS indeed might modulate the threshold for mechanic pain sensation and so might be able to modulate chronic central pain in PD [71].

Acupuncture improved pain, assessed with the KPPS, in PD patients. Pain relief was associated with a modulation of brain connectivity within a painrelated neural network in a resting-state functional magnetic resonance imaging (rs-fMRI) approach [4, 58], suggesting a potential effect of acupuncture on central pain in PD.

\section{NOCICEPTIVE (MUSCULOSKELETAL AND VISCERAL) PAIN}

The recommendations are based on WHO recommendation for pain treatment [86]. However, the WHO guideline was originally developed for painful tumor disorders and contains opiates from escalation 
level two onwards, which is challenging in PD due to potential worsening of disease-related constipation.

Musculoskeletal pain should primarily be treated with antinociceptive pain medication, such as the NSAIDs ibuprofen and diclofenac, metamizol or COX-2 inhibitors. The dose of metamizole should be high enough, i.e., body weight adapted with a single dose preferably of $1000 \mathrm{mg}$ [27]. However, with chronic use of NSAIDs there are not only cardiovascular and nephro-toxic risks but also a high risk for damage to the mucous membrane of the gastrointestinal tract (GI) with ulcers and bleeding. Here selective COX-2 inhibitors have advantages over classic NSAIDs. Proton inhibitors can reduce the risk of lesions in the upper, but not in the middle and lower GI, but they change the microbiome in the gut [87]. This may be particularly relevant for PD patients, given that there are data that a modified microbiome in PD might contribute to the development and progression of the disease [88]. Furthermore, proton inhibitors increase the risk of osteoporosis and vitamin B12 deficiency in PD patients [89-91].

Physiotherapy has been reported by patients to be effective especially against musculoskeletal pain [4], but data regarding specific techniques are missing. Yoga improved low back pain in PD [57].

Oxycodone-naloxone might be effective not only in central but also in nociceptive pain in PD patients, but in the PANDA study [78], prolonged-release oxycodone-naloxone did not have a significant effect on the primary endpoint of improved average $24 \mathrm{~h}$ pain score at 16 weeks in PD patients. Given that the per-protocol analysis showed that appropriate adherence resulted in improved average $24 \mathrm{~h}$ pain scores at 16 weeks of treatment compared with placebo [78, 79], the results of this study highlighted the potential efficacy for patients with PD-related pain and further research might be warranted on this medication.

Based on good experience with dystonic and spastic pain, chronic (nociceptive) pain such as back or shoulder-neck pain, myofascial pain syndrome or enthesis pain, (off-label) injection of botulinum toxin into pain trigger points with or without prior experimental infiltration with a local anesthetic might be helpful [92].

In painful visceral constipation or defecation, methods to improve the intestinal peristaltic and stool consistency are primarily suggested. Patients should be instructed to drink at least 1.5 liter/day, to exercise and to avoid constipating food and medication (opiates!). Locally water binding (macrogol, lactulose) or prokinetically effective substances (e.g., prucalo- pride) can be helpful [93]. Clysters or manual removal might be necessary in constipation within the rectum. In individual cases, endoscopic local application of botulinum toxin can help with painfulmyotonus or spasms in the esophagus, pylorus, anal sphincter [94] or in painful detrusor hyperactivity of the bladder [95]. Painful detrusor-sphincter-dyssynergy or urinary retention might respond to $\alpha 1$-adrenoceptor antagonists and/or preferentially bladder-selective anticholinergics [27].

\section{NEUROPATHIC PAIN}

Gabapentine and pregabaline are well known to be effective in neuropathic pain, to reduce the release of the excitatory neurotransmitter glutamate [81] and therefore are suggested as therapy for this type of pain in PD as well. For both substances, no data regarding pain treatment in PD is available. Gabapentine might be used preferentially, because it has proven to be well tolerated in PD with a potentially positive influence on motor symptoms [82, 83]. Furthermore, the guidelines recommend tricyclic antidepressants or duloxetine for treatment of neuropathic pain. However, tricyclics often deteriorate cognition and/or psychosis especially in the elderly more advanced and in the elder PD patients and can cause sedation. The differential side effect profile of different tricyclics has to be considered here. If necessary, low doses preferably given in the evening should be used. Topical therapies with lidocaine patches or capsaicin can be tried [27].

\section{PAIN AND DEPRESSION}

Despite the high prevalence of depression associated with pain in PD [4, 29, 31-33], the data available on the use of antidepressants in general in PD is limited. Antidepressant effects have been demonstrated in controlled studies for the dopamine receptor agonist pramipexole [96] and the antidepressants nortiptyline [97], desipramine and citalopram [98] and venlafaxine [99]. There were no betweengroup differences in change in pain or anhedonia scores for pramipexol compared to placebo. There is a positive [99] and a negative [97] controlled study for paroxetine. There is little evidence from a meta-analysis for amitriptyline [100]. To avoid anticholinergic side effects, venlafaxine can be an alternative that has proven effective in the treatment of neuropathic pain in diabetic polyneuropathy [101]. 
The antidepressant duloxetine is known to be effective in depression and peripheral neuropathic pain [102] in other patients and has been found effective on central pain in PD [49]. Therefore duloxetine might be helpful in depressed PD patients with neuropathic pain, although the effects on both symptoms have not been investigated in PD patients. Psychological therapy is particularly recommended for depression and pain [27].

\section{PAIN IN RESTLESS LEGS SYNDROME AND PD}

PD patients who receive increasing dopaminergic doses over their disease course could show an increased prevalence of restless legs syndrome (RLS) [103]. First, for the treatment of painful RLS, the compensation of iron deficiency, defined as an iron storage value (ferritin) of less than $50-75 \mu \mathrm{g} / \mathrm{l}$, is recommended [104]. Iron should be applied preferentially intravenously, because efficacy of oral application has not been adequately evaluated [105] and iron given orally can deteriorate constipation and interacts gastrointestinally with levodopa and COMT inhibitors [27]. Of note, drugs that potentially reinforce RLS such as mirtazapine, SSRI or neuroleptics, should be discontinued.

In general, painful RLS in PD should be treated according to the guidelines for idiopathic RLS recommending low-dose dopamine agonists (to avoid augmentation) before night-time as first choice treatment, gabapentine and pregabaline as second line options, and oycodone/naloxone as escalation therapy [105]. In PD, the non-ergoline derivates pramipexole, ropinirole and rotigotine should be preferentially used. Because rotigotine has shown positive effects on PD-associated pain beyond the RLS, it might be preferentially used in painful RLS in PD patients [27].

Carbamazepine and valproic acid were considered likely efficacious in idiopathic RLS [105] but are not suggested in PD due to potential side effects.

\section{SPECIFIC PAIN SYNDROMES IN PD}

Orthostatic hypotension can cause headache or neck ("coat hanger") pain [39]. If necessary, antihypertensive co-medication should be adjusted in accordance with recently given recommendations [106]. Additional measures are physical exercises, (salt-rich) fluid intake, wearing of compression stock- ings class two, and administration of substances such as midodrine, fludrocortisone or, in severe cases, Lthreo-3,4-dihydroxyphenylserine (L -DOPS) [107]. Camptocormia is often accompanied with pain. Prior to therapy the cause has to be differentiated [108]. In addition to the use of pain killers, the focus is on physiotherapy. There is no specific pain medication recommended currently.

Migraine is reported less often in PD, and often associated with depression and sleep disturbances [109]. Therefore the therapy has to focus on the comorbidities as well. The usual medication for migraine can be used, but due to an increased risk for orthostatic hypotension in PD, caution should be exercised with beta blockers [106].

\section{CONCLUSION}

Pain is a very common and QoL impairing symptom in PD. Further efforts are necessary to improve identification, diagnosis and therapy. Treatment should consider the underlying pathophysiology and pharmacological and non-pharmacological supportive procedures should be applied properly and ideally in an interdisciplinary approach with the neurologist as doctor in charge. Because data regarding treatment of pain in PD is limited, treatment concepts proven valid for the specific pain etiologies in other subjects should be considered. Optimization of antiparkinsonian treatment should always be the fundament of treatment. Further research of the nature of pain in PD is necessary to develop specific therapies.

\section{CONFLICT OF INTEREST}

$\mathrm{CB}$ has received fees as speaker and/or advisor from Abbvie, Bial, Desitin, Grünenthal, Licher, Novartis, TAD Pharma, UCB, and Zambon.

JK has received fees as speaker and/or advisor from UCB Pharma, Desitin, Novartis, Bial, Zambon, Medtronic, Desitin, AbbVie, NeuroDerm, and Teva Pharmaceuticals.

WHJ has received fees as speaker and/or advisor from Abbvie, Allergan, Bial, Desitin, Ipsen, Merz, $\mathrm{UCB}$, and Zambon.

\section{REFERENCES}

[1] Barone P, Antonini A, Colosimo C, Marconi R, Morgante L, Avarello TP, Bottacchi E, Cannas A, Ceravolo G, Ceravolo R, Cicarelli G, Gaglio RM, Giglia RM, Iemolo F, Manfredi M, Meco G, Nicoletti A, Pederzoli M, Petrone 
A, Pisani A, Pontieri FE, Quatrale R, Ramat S, Scala R, Volpe G, Zappulla S, Bentivoglio AR, Stocchi F, Trianni G, Dotto PD; PRIAMO study group (2009) The PRIAMO Study: A multicenter assessment of nonmotor symptoms and their impact on quality of life in Parkinson's disease. Mov Disord 24, 1641-1649.

[2] Defazio G, Gigante A, Mancino P, Tinazzi M (2013) The epidemiology of pain in Parkinson's disease. J Neural Transm (Vienna) 120, 583-586.

[3] Politis M, Wu K, Molloy S, Bain G, Chaudhuri KR, Piccini P (2010) Parkinson's disease symptoms: The patient's perspective. Mov Disord 25, 1646-1651.

[4] Buhmann C, Wrobel N, Grashorn W, Fruendt O, Wesemann K, Diedrich S, Bingel U (2017) Pain in Parkinson disease: A cross-sectional survey of its prevalence, specifics, and therapy. J Neurol 264, 758-769.

[5] Beiske AG, Loge JH, Ronningen A, Svensson E (2009) Pain in Parkinson's disease: Prevalence and characteristics. Pain 141, 173-177.

[6] Broen MP, Braaksma MM, Patijn J, Weber WE (2012) Prevalence of pain in Parkinson's disease: A systematic review using the Modified QUADAS Tool. Mov Disord 27, 480-484.

[7] Valkovic P, Minar M, Singliarova H, Harsany J, Hanakova M, Martinkova J, Benetin J (2015) Pain in Parkinson's disease: A cross-sectional study of its prevalence, types, and relationship to depression and quality of life. Plos One 10, e0136541.

[8] Ford B (1998) Pain in Parkinson's disease. Clin Neurosci 5, 63-72.

[9] Wasner G, Deuschl G (2012) Pains in Parkinson diseasemany syndromes under one umbrella. Nat Rev Neurol $\mathbf{8}$, 284-294.

[10] Defazio G, Tinazzi M, Berardelli A (2013) How pain arises in Parkinson's disease? Eur J Neurol 20, 1517-1523.

[11] Lim SY, Evans AH (2011) Pain and paresthesia in Parkinson's disease. In Parkinson's Disease: Non-Motor and Non-Dopaminergic Features, Olanow CW, Stocchi F, Lang AE, eds. Wiley-Blackwell, pp. 315-332.

[12] Braak H, Del Tredici K (2009) Neuroanatomy and pathology of sporadic Parkinson's disease. Adv Anat Embryol Cell Biol 201, 1-119.

[13] Blanchet PJ, Brefel-Courbon C (2018) Chronic pain and pain processing in Parkinson's disease. Prog Neuropsychopharmacol Biol Psychiatry 87 (Pt B), 200-206.

[14] Reichling DB, Levine JD (2011) Pain and death: Neurodegenerative disease mechanisms in the nociceptor. Ann Neurol 69, 13-21.

[15] Tseng MT, Lin CH (2017) Pain in early-stage Parkinson's disease: Implications from clinical features to pathophysiology mechanisms. J Formos Med Assoc 116, 571-581.

[16] Mylius V, Engau I, Teepker M, Stiasny-Kolster K, Schepelmann K, Oertel WH, Lautenbacher S, Möller JC (2009) Pain sensitivity and descending inhibition of pain in Parkinson's disease. J Neurol Neurosurg Psychiatry 80, 24-28.

[17] Mylius V, Pee S, Pape H, Teepker M, Stamelou M, Eggert K, Lefaucheur JP, Oertel WH, Möller JC (2016) Experimental pain sensitivity in multiple system atrophy and Parkinson's disease at an early stage. Eur J Pain 20, 12231228.

[18] Brefel-Courbon C, Payoux P, Thalamas C, Ory F, Quelven I, Chollet F, Montastruc JL, Rascol O (2005) Effect of levodopa on pain threshold in Parkinson's disease: A clinical and positron emission tomography study. Mov Disord 20,
1557-1563.

[19] Gerdelat-Mas A, Simonetta-Moreau M, Thalamas C, OryMagne F, Slaoui T, Rascol O, Brefel-Courbon C (2007) Levodopa raises objective pain threshold in Parkinson's disease: A RIII reflex study. J Neurol Neurosurg Psychiatry 78, 1140-1142.

[20] Moreno CB, Hernandez-Beltran N, Munevar D, GutierrezAlvarez AM (2012) Central neuropathic pain in Parkinson's disease. Neurologia 27, 500-503.

[21] Grashorn W, Schunke O, Buhmann C, Forkmann K, Diedrich S, Wesemann K, Bingel U (2015) Influence of dopaminergic medication on conditioned pain modulation in Parkinson's disease patients. PLoS One 10, e0135287.

[22] Zambito MS, Tinazzi M, Vitaliani R, Recchia S, Fabris F, Marchini C, Fiaschi A, Moretto G, Giometto B, Macerollo A, Defazio G (2011) Spontaneous pain, pain threshold, and pain tolerance in Parkinson's disease. J Neurol 258, 627-633.

[23] Sung S, Vijiaratnam N, Chan DWC, Farrell M, Evans AH (2018) Pain sensitivity in Parkinson's disease: Systematic review and meta-analysis. Parkinsonism Relat Disord 48, 17-27.

[24] Tinazzi M, Del Vesco C, Fincati E, Ottaviani S, Smania N, Moretto G, Fiaschi A, Martino D, Defazio G (2006) Pain and motor complications in Parkinson's disease. J Neurol Neurosurg Psychiatry 77, 822-825.

[25] Storch A, Schneider CB, Wolz M, Sturwald Y, Nebe A, Odin P, Mahler A, Fuchs G, Jost WH, Chaudhuri KR, Koch R, Reichmann H, Ebersbach G (2013) Nonmotor fluctuations in Parkinson disease: Severity and correlation with motor complications. Neurology 80, 800-809.

[26] Farnikova K, Krobot A, Kanovsky P (2012) Musculoskeletal problems as an initial manifestation of Parkinson's disease: A retrospective study. J Neurol Sci 319, 102-104

[27] Buhmann C, Ip CW, Oehlwein C, Tonges L, Wolz M, Reichmann H, Kassubek J (2018) [Parkinson disease and pain - diagnostic and therapeutic approaches to a challenging non-motor symptom]. Fortschr Neurol Psychiatr 86, S48-S58.

[28] Zella MAS, May C, Muller T, Ahrens M, Tonges L, Gold R, Marcus K, Woitalla D (2019) Landscape of pain in Parkinson's disease: Impact of gender differences. Neurol Res 41, 87-97.

[29] Greenbaum L, Tegeder I, Barhum Y, Melamed E, Roditi Y, Djaldetti R (2012) Contribution of genetic variants to pain susceptibility in Parkinson disease. Eur J Pain 16, 1243-1250.

[30] Li W, Chen Y, Yin B, Zhang L (2014) Pain in Parkinson's disease associated with COMT gene polymorphisms. Behav Neurol 2014, 304203.

[31] Negre-Pages L, Regragui W, Bouhassira D, Grandjean H, Rascol O, DoPaMiP Study Group (2008) Chronic pain in Parkinson's disease: The cross-sectional French DoPaMiP survey. Mov Disord 23, 1361-1369.

[32] Ehrt U, Larsen JP, Aarsland D (2009) Pain and its relationship to depression in Parkinson disease. Am J Geriatr Psychiatry 17, 269-275.

[33] Rana AQ, Qureshi ARM, Rahman N, Mohammed A, Sarfraz Z, Rana R (2017) Disability from pain directly correlated with depression in Parkinson's disease. Clin Neurol Neurosurg 160, 1-4.

[34] Ford B (2010) Pain in Parkinson's disease. Mov Disord 25(Suppl 1), S98-103. 
[35] Chaudhuri KR, Rizos A, Trenkwalder C, Rascol O, Pal S, Martino D, Carroll C, Paviour D, Falup-Pecurariu C, Kessel B, Silverdale M, Todorova A, Sauerbier A, Odin P, Antonini A, Martinez-Martin P, EUROPAR and the IPMDS Non Motor PD Study Group (2015) King's Parkinson's disease pain scale, the first scale for pain in PD: An international validation. Mov Disord 30, 1623-1631.

[36] Lin CH, Wu RM, Chang HY, Chiang YT, Lin HH (2013) Preceding pain symptoms and Parkinson's disease: A nationwide population-based cohort study. Eur J Neurol 20, 1398-1404.

[37] Hanagasi HA, Akat S, Gurvit H, Yazici J, Emre M (2011) Pain is common in Parkinson's disease. Clin Neurol Neurosurg 113, 11-13.

[38] Joseph C, Jonsson-Lecapre J, Wicksell R, Svenningsson P, Franzen E (2019) Pain in persons with mild-moderate Parkinson's disease: A cross-sectional study of pain severity and associated factors. Int J Rehabil Res 42, 371-376.

[39] Bleasdale-Barr KM, Mathias CJ (1998) Neck and other muscle pains in autonomic failure: Their association with orthostatic hypotension. J R Soc Med 91, 355-359.

[40] Jost WH, Buhmann C (2019) The challenge of pain in the pharmacological management of Parkinson's disease. Expert Opin Pharmacother 20, 1847-1854.

[41] Van Der Steen JT, Lennaerts H, Hommel D, Augustijn B, Groot M, Hasselaar J, Bloem BR, Koopmans RTCM (2019) Dementia and Parkinson's disease: Similar and divergent challenges in providing palliative care. Front Neurol 10, 54.

[42] Lennaerts H, Groot M, Rood B, Gilissen K, Tulp H, van Wensen E, Munneke M, van Laar T, Bloem BR (2017) A guideline for Parkinson's disease nurse specialists, with recommendations for clinical practice. J Parkinsons Dis 7, 749-754.

[43] Lennaerts H, Steppe M, Munneke M, Meinders MJ, van der Steen JT, van den Brand M, van Amelsvoort D, Vissers K, Bloem BR, Groot M (2019) Palliative care for persons with Parkinson's disease: A qualitative study on the experiences of health care professionals. BMC Palliat Care $\mathbf{1 8}$, 53.

[44] Ha AD, Jankovic J (2012) Pain in Parkinson's disease. Mov Disord 27, 485-491.

[45] Quinn NP, Koller WC, Lang AE, Marsden CD (1986) Painful Parkinson's Disease. Lancet 1, 1366-1369.

[46] Nebe A, Ebersbach G (2009) Pain intensity on and off levodopa in patients with Parkinson's disease. Mov Disord 24, 1233-1237.

[47] Qureshi AR, Rana AQ, Malik SH, Rizvi SFH, Akhter S, Vannabouathong C, Sarfraz Z, Rana R (2018) Comprehensive examination of therapies for pain in Parkinson's disease: A systematic review and meta-analysis. Neuroepidemiology 51, 190-206.

[48] Csoti I, Herbst H, Urban P, Woitalla D, Wullner U (2019) Polypharmacy in Parkinson's disease: Risks and benefits with little evidence. J Neural Transm (Vienna) 126, 871878.

[49] Djaldetti R, Yust-Katz S, Kolianov V, Melamed E, Dabby $R$ (2007) The effect of duloxetine on primary pain symptoms in Parkinson disease. Clin Neuropharmacol 30, 201-205.

[50] Lotan I, Treves TA, Roditi Y, Djaldetti R (2014) Cannabis (medical marijuana) treatment for motor and non-motor symptoms of Parkinson disease: An open-label observational study. Clin Neuropharmacol 37, 41-44.
[51] Shohet A, Khlebtovsky A, Roizen N, Roditi Y, Djaldetti R (2017) Effect of medical cannabis on thermal quantitative measurements of pain in patients with Parkinson's disease. Eur J Pain 21, 486-493.

[52] Cury RG, Galhardoni R, Teixeira MJ, Dos Santos Ghilardi MG, Silva V, Myczkowski ML, Marcolin MA, Barbosa ER, Fonoff ET, Ciampi de Andrade D (2016) Subthalamic deep brain stimulation modulates conscious perception of sensory function in Parkinson's disease. Pain 157, 27582765.

[53] Cury RG, Galhardoni R, Fonoff ET, Dos Santos Ghilardi MG, Fonoff F, Arnaut D, Myczkowski ML, Marcolin MA, Bor-Seng-Shu E, Barbosa ER, Teixeira MJ, Ciampi de Andrade D (2014) Effects of deep brain stimulation on pain and other nonmotor symptoms in Parkinson disease. Neurology 83, 1403-1409.

[54] Gandolfi M, Geroin C, Antonini A, Smania N, Tinazzi M (2017) Understanding and treating pain syndromes in Parkinson's disease. Int Rev Neurobiol 134, 827-858.

[55] Jung YJ, Kim HJ, Jeon BS, Park H, Lee WW, Paek SH (2015) An 8-year follow-up on the effect of subthalamic nucleus deep brain stimulation on pain in Parkinson disease. JAMA Neurol 72, 504-510.

[56] Deuschl G, Schade-Brittinger C, Krack P, Volkmann J, Schäfer H, Bötzel K, Daniels C, Deutschländer A, Dillmann U, Eisner W, Gruber D, Hamel W, Herzog J, Hilker R, Klebe S, Kloss M, Koy J, Krause M, Kupsch A, Lorenz D, Lorenzl S, Mehdorn HM, Moringlane JR, Oertel W, Pinsker MO, Reichmann H, Reuss A, Schneider GH, Schnitzler A, Steude U, Sturm V, Timmermann L, Tronnier V, Trottenberg T, Wojtecki L, Wolf E, Poewe W, Voges J; German Parkinson Study Group, Neurostimulation Section (2006) A randomized trial of deep-brain stimulation for Parkinson's disease. N Engl J Med 355, 896-908.

[57] Myers PS, Harrison EC, Rawson KS, Horin AP, Sutter EN, Mcneely ME, Earhart GM (2019) Yoga improves balance and low-back pain, but not anxiety, in people with Parkinson's disease. Int J Yoga Therap, doi: 10.17761/2020-D-18-00028.

[58] Yu SW, Lin SH, Tsai CC, Chaudhuri KR, Huang YC, Chen YS, Yeh BY, Wu YR, Wang JJ (2019) Acupuncture effect and mechanism for treating pain in patients with Parkinson's disease. Front Neurol 10, 1114.

[59] Fil A, Cano-De-La-Cuerda R, Munoz-Hellin E, Vela L, Ramiro-Gonzalez M, Fernandez-De-Las-Penas C (2013) Pain in Parkinson disease: A review of the literature. Parkinsonism Relat Disord 19, 285-294.

[60] Oichi T, Chikuda H, Ohya J, Ohtomo R, Morita K, Matsui H, Fushimi K, Tanaka S, Yasunaga H (2017) Mortality and morbidity after spinal surgery in patients with Parkinson's disease: A retrospective matched-pair cohort study. Spine $J$ 17, 531-537.

[61] Skogar O, Lokk J (2016) Pain management in patients with Parkinson's disease: Challenges and solutions. J Multidiscip Healthc 9, 469-749.

[62] Rana AQ, Kabir A, Jesudasan M, Siddiqui I, Khondker S (2013) Pain in Parkinson's disease: Analysis and literature review. Clin Neurol Neurosurg 115, 2313-2317.

[63] Cattaneo C, Barone P, Bonizzoni E, Sardina M (2017) Effects of safinamide on pain in fluctuating Parkinson's disease patients: A post-hoc analysis. J Parkinsons Dis 7, 95-101.

[64] Olanow CW, Kieburtz K, Stern M, Watts R, Langston JW, Guarnieri M, Hubble J (2004) Double-blind, placebocontrolled study of entacapone in levodopa-treated 
patients with stable Parkinson disease. Arch Neurol 61, 1563-1568.

[65] Rascol O, Bronzova J, Hauser RA, Lang AE, Sampaio C, Theeuwes A, Van De Witte SV (2012) Pardoprunox as adjunct therapy to levodopa in patients with Parkinson's disease experiencing motor fluctuations: Results of a double-blind, randomized, placebo-controlled, trial. Parkinsonism Relat Disord 18, 370-376.

[66] Antonini A, Yegin A, Preda C, Bergmann L, Poewe W, GLORIA study investigators and coordinators (2015) Global long-term study on motor and non-motor symptoms and safety of levodopa-carbidopa intestinal gel in routine care of advanced Parkinson's disease patients; 12 month interim outcomes. Parkinsonism Relat Disord 21, 231-235.

[67] Zibetti M, Merola A, Artusi CA, Rizzi L, Angrisano S, Reggio D, De Angelis C, Rizzone M, Lopiano L (2014) Levodopa/carbidopa intestinal gel infusion in advanced Parkinson's disease: A 7-year experience. Eur J Neurol 21, 312-318.

[68] Perez-Lloret S, Rey MV, Dellapina E, Pellaprat J, BrefelCourbon C, Rascol O (2012) Emerging analgesic drugs for Parkinson's disease. Expert Opin Emerg Drugs 17, 157171.

[69] Rieu I, Degos B, Castelnovo G, Vial C, Durand E, Pereira B, Simonetta-Moreau M, Sangla S, Fluchère F, Guehl D, Burbaud P, Geny C, Gayraud D, Ory-Magne F, Bouhour F, Llinares E, Derost P, Marques A, Durif F (2018) Incobotulinum toxin A in Parkinson's disease with foot dystonia: A double blind randomized trial. Parkinsonism Relat Disord 46, 9-15

[70] Bruno V, Freitas ME, Mancini D, Lui JP, Miyasaki J, Fox SH (2018) Botulinum toxin type A for pain in advanced Parkinson's disease. Can J Neurol Sci 45, 23-29.

[71] Belasen A, Rizvi K, Gee LE, Yeung P, Prusik J, RamirezZamora A, Hanspal E, Paiva P, Durphy J, Argoff CE, Pilitsis JG (2017) Effect of low-frequency deep brain stimulation on sensory thresholds in Parkinson's disease. $J$ Neurosurg 126, 397-403.

[72] Trenkwalder C, Kies B, Rudzinska M, Fine J, Nik1 J, Honczarenko K, Dioszeghy P, Hill D, Anderson T, Myllyla V, Kassubek J, Steiger M, Zucconi M, Tolosa E, Poewe W, Surmann E, Whitesides J, Boroojerdi B, Chaudhuri KR (2011) Rotigotine effects on early morning motor function and sleep in Parkinson's disease: A double-blind, randomized, placebo-controlled study (RECOVER). Mov Disord 26, 90-99.

[73] Kassubek J, Chaudhuri KR, Zesiewicz T, Surmann E, Boroojerdi B, Moran K, Ghys L, Trenkwalder C (2014) Rotigotine transdermal system and evaluation of pain in patients with Parkinson's disease: A post hoc analysis of the RECOVER study. BMC Neurol 14, 42.

[74] Rascol O, Zesiewicz T, Chaudhuri KR, Asgharnejad M, Surmann E, Dohin E, Nilius S, Bauer L (2016) A randomized controlled exploratory pilot study to evaluate the effect of rotigotine transdermal patch on Parkinson's disease-associated chronic pain. J Clin Pharmacol 56, 852-861.

[75] Cattaneo C, Kulisevsky J, Tubazio V, Castellani P (2018) Long-term efficacy of safinamide on Parkinson's disease chronic pain. Adv Ther 35, 515-522.

[76] Buhmann C, Mainka T, Ebersbach G, Gandor F (2019) Evidence for the use of cannabinoids in Parkinson's disease. J Neural Transm (Vienna) 126, 913-924.
[77] Meissner W, Leyendecker P, Mueller-Lissner S, Nadstawek J, Hopp M, Ruckes C, Wirz S, Fleischer W, Reimer K (2009) A randomised controlled trial with prolongedrelease oral oxycodone and naloxone to prevent and reverse opioid-induced constipation. Eur J Pain 13, 56-64.

[78] Trenkwalder C, Chaudhuri KR, Martinez-Martin P, Rascol O, Ehret R, Valis M, Sátori M, Krygowska-Wajs A, Marti MJ, Reimer K, Oksche A, Lomax M, DeCesare J, Hopp M; PANDA study group (2015) Prolongedrelease oxycodone-naloxone for treatment of severe pain in patients with Parkinson's disease (PANDA): A doubleblind, randomised, placebo-controlled trial. Lancet Neurol 14, 1161-1170.

[79] Madeo G, Schirinzi T, Natoli S, Pierantozzi M, Stefani A, Dauri M, Pisani A (2015) Efficacy and safety profile of prolonged release oxycodone in combination with naloxone (OXN PR) in Parkinson's disease patients with chronic pain. J Neurol 262, 2164-2170.

[80] Watson CJ (2016) Insular balance of glutamatergic and gabaergic signaling modulates pain processing. Pain 157, 2194-2207.

[81] Quintero JE, Dooley DJ, Pomerleau F, Huettl P, Gerhardt GA (2011) Amperometric measurement of glutamate release modulation by gabapentin and pregabalin in rat neocortical slices: Role of voltage-sensitive $\mathrm{Ca} 2+$ Alpha2delta-1 subunit. J Pharmacol Exp Ther 338, 240245.

[82] Olson WL, Gruenthal M, Mueller ME, Olson WH (1997) Gabapentin for Parkinsonism: A double-blind, placebocontrolled, crossover trial. Am J Med 102, 60-66.

[83] Van Blercom N, Lasa A, Verger K, Masramon X, Sastre VM, Linazasoro G (2004) Effects of gabapentin on the motor response to levodopa: A double-blind, placebocontrolled, crossover study in patients with complicated Parkinson disease. Clin Neuropharmacol 27, 124-128.

[84] Timmermann L, Oehlwein C, Ransmayr G, Frohlich H, Will E, Schroeder H, Lauterbach T, Bauer L, Kassubek J (2017) Patients' perception of Parkinson's diseaseassociated pain following initiation of rotigotine: A multicenter non-interventional study. Postgrad Med 129, 46-54.

[85] Gierthmuhlen J, Arning P, Binder A, Herzog J, Deuschl G, Wasner G, Baron R (2010) Influence of deep brain stimulation and levodopa on sensory signs in Parkinson's disease. Mov Disord 25, 1195-1202.

[86] World Health Organization (1996) Cancer Pain Relief. With a Guide to Opioid Availability. WHO, Geneva.

[87] Scarpignato C, Dolak W, Lanas A, Matzneller P, Renzulli C, Grimaldi M, Zeitlinger M, Bjarnason I (2017) Rifaximin reduces the number and severity of intestinal lesions associated with use of nonsteroidal anti-inflammatory drugs in humans. Gastroenterology 152, 980-982.

[88] Minato T, Maeda T, Fujisawa Y, Tsuji H, Nomoto K, Ohno K, Hirayama M (2017) Progression of Parkinson's disease is associated with gut dysbiosis: Two-year follow-up study. PLoS One 12, e0187307.

[89] Shen L (2015) Associations between B vitamins and Parkinson's disease. Nutrients 7, 7197-7208.

[90] Metta V, Sanchez TC, Padmakumar C (2017) Osteoporosis: A hidden nonmotor face of Parkinson's disease. Int Rev Neurobiol 134, 877-890.

[91] Maes ML, Fixen DR, Linnebur SA (2017) Adverse effects of proton-pump inhibitor use in older adults: A review of the evidence. Ther Adv Drug Saf 8, 273-297. 
[92] Placek R, Jerosch J, Reißig, A, Söhling (2006) Botulinumtoxin. In Orthopadie Und Sportmedizin. 1. Auflage Ed. Uni-Med Verlag AG, Bremen.

[93] Palma JA, Kaufmann H (2018) Treatment of autonomic dysfunction in Parkinson disease and other synucleinopathies. Mov Disord 33, 372-390.

[94] Triadafilopoulos G, Gandhy R, Barlow C (2017) Pilot cohort study of endoscopic botulinum neurotoxin injection in Parkinson's disease. Parkinsonism Relat Disord 44, 33-37.

[95] Anderson RU, Orenberg EK, Glowe P (2014) Onabotulinumtoxina office treatment for neurogenic bladder incontinence in Parkinson's disease. Urology 83, 22-27.

[96] Barone P, Poewe W, Albrecht S, Debieuvre C, Massey D, Rascol O, Tolosa E, Weintraub D (2010) Pramipexole for the treatment of depressive symptoms in patients with Parkinson's disease: A randomised, double-blind, placebo-controlled trial. Lancet Neurol 9, 573-580.

[97] Menza M, Dobkin RD, Marin H, Mark MH, Gara M, Buyske S, Bienfait K, Dicke A (2009) A controlled trial of antidepressants in patients with Parkinson disease and depression. Neurology 72, 886-892.

[98] Devos D, Dujardin K, Poirot I, Moreau C, Cottencin O, Thomas P, Destée A, Bordet R, Defebvre L (2008) Comparison of desipramine and citalopram treatments for depression in Parkinson's disease: A double-blind, randomized, placebo-controlled study. Mov Disord 23, 850-857.

[99] Richard IH, Mcdermott MP, Kurlan R, Lyness JM, Como PG, Pearson N, Factor SA, Juncos J, Serrano Ramos C, Brodsky M, Manning C, Marsh L, Shulman L, Fernandez HH, Black KJ, Panisset M, Christine CW, Jiang W, Singer C, Horn S, Pfeiffer R, Rottenberg D, Slevin J, Elmer L, Press D, Hyson HC, McDonald W; SAD-PD Study Group (2012) A randomized, double-blind, placebo-controlled trial of antidepressants in Parkinson disease. Neurology 78, 1229-1236.

[100] Miyasaki JM, Shannon K, Voon V, Ravina B, KleinerFisman G, Anderson K, Shulman LM, Gronseth G, Weiner WJ; Quality Standards Subcommittee of the American Academy of Neurology (2006) Practice parameter: Evaluation and treatment of depression, psychosis, and dementia in Parkinson disease (an evidence-based review): Report of the quality standards subcommittee of the American Academy of Neurology. Neurology 66, 996-1002.

[101] Rowbotham MC, Goli V, Kunz NR, Lei D (2004) Venlafaxine extended release in the treatment of painful diabetic neuropathy: A double-blind, placebo-controlled study. Pain 110, 697-706.

[102] Attal N, Cruccu G, Baron R, Haanpaa M, Hansson P, Jensen TS, Nurmikko T; European Federation of Neurological Societies (2010) EFNS guidelines on the pharmacological treatment of neuropathic pain: 2010 revision. Eur J Neurol 17, 1113-e88.

[103] Trenkwalder C, Allen R, Hogl B, Clemens S, Patton S, Schormair B, Winkelmann J (2018) Comorbidities, treatment, and pathophysiology in restless legs syndrome. Lancet Neurol 17, 994-1005.

[104] Hornyak M, Scholz H, Kohnen R, Bengel J, Kassubek J, Trenkwalder C (2014) What treatment works best for restless legs syndrome? Meta-analyses of dopaminergic and non-dopaminergic medications. Sleep Med Rev 18, 153-164.

[105] Winkelmann J, Allen RP, Hogl B, Inoue Y, Oertel W, Salminen AV, Winkelman JW, Trenkwalder C, Sampaio C (2018) Treatment of restless legs syndrome: Evidencebased review and implications for clinical practice (revised 2017). Mov Disord 33, 1077-1091.

[106] Jost WH (2020) What are the considerations for anti-hypertensive treatment in patients with Parkinson's disease? Expert Opin Pharmacother, doi: 10.1080/14656566.2020.1744565.

[107] Wasner G, Baron R (2000) Orthostatic dysregulationsymptoms, pathophysiology and treatment. Akt Neurol 27, 157-169.

[108] Fasano A, Geroin C, Berardelli A, Bloem BR, Espay AJ, Hallett M, Lang AE, Tinazzi M (2018) Diagnostic criteria for camptocormia in Parkinson's disease: A consensusbased proposal. Parkinsonism Relat Disord 53, 53-57.

[109] Suzuki K, Okuma Y, Uchiyama T, Miyamoto M, Sakakibara R, Shimo Y, Hattori N, Kuwabara S, Yamamoto T, Kaji Y, Hirano S, Suzuki S, Haruyama Y, Kobashi G, Hirata K; Kanto NMPD investigators (2018) The prevalence, course and clinical correlates of migraine in Parkinson's disease: A multicentre case-controlled study. Cephalalgia 38, 1535-1544. 